\title{
The African Swine Fever Virus with MGF360 and MGF505 Deleted Reduces the Apoptosis of Porcine Alveolar Macrophages by Inhibiting the NF- $\kappa B$ Signaling Pathway and Interleukin-1 $\beta$
}

\author{
Qi Gao ${ }^{1,2}$, Yunlong Yang ${ }^{1,3}$, Weipeng Quan ${ }^{1,4}$, Jiachen Zheng ${ }^{1,4}$, Yizhuo Luo ${ }^{1,3}$, Heng Wang ${ }^{1,2,3}$, \\ Xiongnan Chen ${ }^{1,4}$, Zhao Huang ${ }^{1,4}$, Xiaojun Chen ${ }^{1,4}$, Runda Xu ${ }^{1,4}$, Guihong Zhang ${ }^{1,2, *}$ and Lang Gong ${ }^{1,2,4, *}$ \\ 1 Key Laboratory of Zoonosis Prevention and Control of Guangdong Province, College of Veterinary Medicine, \\ South China Agricultural University, Guangzhou 510462, China; qigao2021@scau.edu.cn (Q.G.); \\ yunlongyang@stu.scau.edu.cn (Y.Y.); weipengquan@stu.scau.edu.cn (W.Q.); zhengj@@stu.scau.edu.cn (J.Z.); \\ lawzz@stu.scau.edu.cn (Y.L.); wangheng2009@scau.edu.cn (H.W.); cxn201314@stu.scau.edu.cn (X.C.); \\ yingwenmulu@stu.scau.edu.cn (Z.H.); xiaojunchen@stu.scau.edu.cn (X.C.); 18819255305@163.com (R.X.) \\ 2 Maoming Branch, Guangdong Laboratory for Lingnan Modern Agriculture, Maoming 525000, China \\ 3 Research Center for African Swine Fever Prevention and Control, South China Agricultural University, \\ Guangzhou 510642, China \\ 4 African Swine Fever Regional Laboratory of China (Guangzhou), Guangzhou 510642, China \\ * Correspondence: guihongzh@scau.edu.cn (G.Z.); gonglang@scau.edu.cn (L.G.)
}

Citation: Gao, Q.; Yang, Y.; Quan, W.; Zheng, J.; Luo, Y.; Wang, H.; Chen, X.; Huang, Z.; Chen, X.; Xu, R.; et al. The African Swine Fever Virus with MGF360 and MGF505 Deleted

Reduces the Apoptosis of Porcine Alveolar Macrophages by Inhibiting the NF- $\kappa$ B Signaling Pathway and Interleukin-1 $\beta$. Vaccines 2021, 9, 1371. https://doi.org/10.3390/

vaccines 9111371

Academic Editor: François Meurens

Received: 25 August 2021

Accepted: 13 November 2021

Published: 22 November 2021

Publisher's Note: MDPI stays neutral with regard to jurisdictional claims in published maps and institutional affiliations.

Copyright: (c) 2021 by the authors. Licensee MDPI, Basel, Switzerland. This article is an open access article distributed under the terms and conditions of the Creative Commons Attribution (CC BY) license (https:// creativecommons.org/licenses/by/ $4.0 /)$.
Abstract: African swine fever virus (ASFV) poses serious threats to the swine industry. The mortality rate of African swine fever (ASF) is $100 \%$, and there is no effective vaccine currently available. Complex immune escape strategies of ASFV are crucial factors affecting immune prevention and vaccine development. CD2v and MGF360-505R genes have been implicated in the modulation of the immune response. The molecular mechanisms contributing to innate immunity are poorly understood. In this study, we discover the cytopathic effect and apoptosis of $\Delta C D 2 v / \Delta M G F 360-505 R-$ ASFV after infection in porcine alveolar macrophages (PAMs) was significantly less than wild-type ASFV. We demonstrated that CD2v- and MGF360-505R-deficient ASFV decrease the level of apoptosis by inhibiting the NF- $\mathrm{B}$ signaling pathway and IL-1 $\beta$ mRNA transcription. Compared with wildtype ASFV infection, the levels of phospho-NF- $\kappa$ B p 65 and p-I $\kappa B$ protein decreased in CD2v- and MGF360-505R-deficient ASFV. Moreover, CD2v- and MGF360-505R-deficient ASFV induced less IL-1 $\beta$ production than wild-type ASFV and was attenuated in replication compared with wild-type ASFV. We further found that MGF360-12L, MGF360-13L, and MGF-505-2R suppress the promoter activity of NF- $\mathrm{KB}$ by reporter assays, and CD2v activates the NF- $\mathrm{KB}$ signaling pathway. These findings suggested that CD2v- and MGF360-505R-deficient ASFV could reduce the level of ASFV p30 and the apoptosis of PAMs by inhibiting the NF- $\mathrm{kB}$ signaling pathway and IL- $1 \beta$ mRNA transcription, which might reveal a novel strategy for ASFV to maintain the replication of the virus in the host.

Keywords: African swine fever virus; MGF; CD2v; NF-kB; IL-1 ; apoptosis

\section{Introduction}

African swine fever (ASF) is a highly pathogenic animal infectious disease caused by the African swine fever virus (ASFV) infecting domestic pigs and wild boars, causing huge economic losses to the pig industry [1]. ASFV was first reported in Kenya in 1921, and the disease is spreading in Africa, Europe, and Asia, posing a serious threat to the global economy and ecology [2,3]. The lethality rate of ASFV high-viral strain infection is as high as $100 \%$, while the low-viral strain can cause latent infection of the host, and animals can therefore develop immunity against this strain [4]. However, there is currently no effective ASFV vaccine for prevention and control, and no drugs have been approved to treat ASF [5]. ASFV infection can evade the host's defense system and thus escape the 
host's innate antiviral immunity to ASFV [6]. The huge genome and complex immune escape mechanism of ASFV pose a huge challenge to the development of high-efficiency ASFV vaccine [7].

ASFV is a DNA arbovirus and the only member of the family Asfarviridae [8]. ASFV is an icosahedral virus, encoding a linear dsDNA genome of 165 genes, with a genome length of 170-190 kb [9]. Previous studies have shown that ASFV protein can inhibit the host's defense mechanism, which is of great significance for the immune escape built by the virus and the maintenance of virus replication [10]. Studies have shown that deleting virulence genes related to virus virulence from the ASFV genome can be used to develop ASFV live attenuated vaccines [1]. The CD2v protein of ASFV plays an important role in the spread of the virus and the immune escape mechanism. It can induce the infected cells to adsorb pig red blood cells in a rosetting of erythrocytes (haemadsorbtion or HAD) [11]. It is also a protein necessary for the adsorption of virus particles and pig red blood cells $[12,13]$. The $\mathrm{pCD} 2 \mathrm{v} / \mathrm{pEP} 402 \mathrm{R}$ protein is the only protein that clearly exists on the outer envelope of virus particles, and it has been found to play an important role in ASFV invading cells or spreading between cells [14]. In a study, it was found that deletion of the EP402R gene encoding the CD2v protein of ASFV delayed the appearance of clinical symptoms and reduced the spread of the virus, but did not reduce the mortality rate of viral infections [15]. A recent study showed that deleting the EP402R gene of the BA71V virulent strain will weaken the virulence of the virulent strain and produce protection against the virulent strain [16]. There are five multi-gene families in ASFV, including MGF-100, MGF-110, MGF-300, MGF-360, and MGF-505. They can regulate the host's immune response mechanism and have host specificity $[17,18]$, however, the functions and mechanisms of these multi-gene families have not yet been thoroughly studied. Among them, the two families of MGF360 and MGF505 exist in the highly variable left-end genomic region and encode products with structural similarity $[17,19]$. Therefore, the study of MGF360 and MGF505 regions may clarify their role in ASFV replication and their contribution to virus virulence. Studies have shown that deleting the MGF gene in the BA71V strain adapted to Vero cells will reduce the virus replication in macrophages $[20,21]$. In addition, studies have reported that the MGF360 and MGF505 genes are essential for the virus replication in ticks [22]. There are also reports that the genes in the MGF360 and MGF505 regions have the function of inhibiting host interferon (IFN) production [9]. MGF360 and MGF505 are related to the host specificity, innate immune mechanism, and virulence of ASFV; deletion of MGF will reduce the virulence of ASFV [1].

Nuclear factor-kappa B (NF-kappa B) is a family of transcription factors that can regulate many genes involved in immunity, inflammation, and apoptosis [23]. For a long time, the NF- $\mathrm{kB}$ pathway has been regarded as a typical pro-inflammatory signal transduction pathway. Pro-inflammatory factors such as interleukin 1 (IL-1) and tumor necrosis factor $\alpha$ (TNF- $\alpha$ ) have an activating effect on NF- $k B$. The activation of the NF- $k B$ signaling pathway can promote the secretion of inflammatory factors, chemokines, and adhesion molecules [24]. However, inflammation is a complex physiological process, and the inflammatory response is characterized by coordinating and regulating the secretion of pro-inflammatory and anti-inflammatory factors and the activity of various signal transduction pathways [23,25]. NF- $\mathrm{kB}$ activation is also widely involved in inflammatory diseases, and many studies have focused on the development of anti-inflammatory drugs for NF$\kappa B$ [26]. As generally recognized, NF-kappaB exerts an anti-apoptotic action, promoting the survival of defective cells, which may result in the development of several viruses. Nevertheless, recent reports also point to a pro-apoptotic activity of NF-kappaB [27]. A recent study showed that $\mathrm{HO}-1$ can inhibit IL- $1 \beta$-induced host cell apoptosis by inhibiting the activity of NF- $\mathrm{KB}$ [28].

Here we report the construction of a recombinant virus $\triangle \mathrm{CD} 2 \mathrm{v} / \triangle \mathrm{MGF} 360-505 \mathrm{R}-\mathrm{ASFV}$ derived from the highly virulent GZ201801-ASFV by specifically deleting the genes CD2v and MGF360-505R: MGF505-1R, MGF360-12L, MGF360-13L, MGF360-14L, MGF505-2R, and MGF505-3R. ASFV- $\Delta C D 2 v / \triangle M G F 360-505 R$ replicates efficiently in primary swine 
macrophage cell cultures lower than the parental virus. The cytopathic effect of $\triangle \mathrm{CD} 2 \mathrm{v}$ / $\triangle$ MGF360-505R-ASFV after infection with PAMs was significantly less than GZ201801ASFV. Co-infection with $\Delta C D 2 v / \Delta$ MGF360-505R-ASFV and GZ201801-ASFV can reduce the cytopathic effect of PAMs cells. $\triangle \mathrm{CD} 2 \mathrm{v} / \triangle \mathrm{MGF360-505R-ASFV}$ can down-regulate phosphorylation levels of NF- $\kappa B$ and I $\mathrm{kB}$, and decrease the level of IL- $1 \beta$ expression. In reporter assays, expression of MGF360-12L, MGF360-13L, and MGF505-2R inhibited the NF- $\mathrm{kB}$ promoter. Found in the Western blot experiment, CD2v activates the NF- $\mathrm{kB}$ signaling pathway. Detection by flow cytometry showed that $\triangle \mathrm{CD} 2 \mathrm{v} / \triangle \mathrm{MGF} 360-505 \mathrm{R}-$ ASFV infection induced apoptosis of PAMs significantly less than GZ201801-ASFV. Our study explored the relations between the NF- $\mathrm{kB}$ signaling pathway and apoptosis in ASFV infection, which may help us better understand the pathogenic mechanism of ASFV.

\section{Materials and Methods}

\subsection{Cell Culture and Virus}

Primary porcine alveolar macrophages (PAMs) were collected from 20-30 day-old SPF (Specific Pathogen Free, SPF) pigs. The study is meaningless in the case of co-infections in the porcine respiratory tract; it will affect the study of the interaction between a single pathogen and the host [29]. Therefore, we found that ASFV, PRV, CSFV, SIV, PCV2, and PRRSV pathogens and antibodies were negative through the pathogenic detection of PAMs. CD163 and CD169 are proteins specifically expressed on the surface of macrophages [30,31]. Therefore, the expression of CD163 and CD169 proteins on the cell surface were detected by flow cytometry, and the result shows that the purity of PAMs is approximately 98\% (Figure S1). The high virulence, hemadsorbing ASFV isolate GZ201801 (GenBank: MT496893.1) was isolated in Guangzhou, China, and is p72 genotype II. GZ201801-ASFV, $\triangle \mathrm{CD} 2 \mathrm{v} / \triangle \mathrm{MGF} 360-505 \mathrm{R}-\mathrm{ASFV}, \triangle \mathrm{CD} 2 \mathrm{v}-\mathrm{ASFV}$, and $\triangle \mathrm{MGF360-505R-ASFV}$ are preserved in the Infectious Diseases Laboratory of South China Agricultural University. Viruses were inoculated in PAMs, cultured in RPMI 1640 (Gibco, Waltham, MA, USA), and supplemented with $10 \%$ fetal bovine serum (FBS; Gibco) in a $37^{\circ} \mathrm{C}$ incubator with $5 \% \mathrm{CO}_{2}$. PK-15 cells were maintained in Dulbecco's Modified Eagle's Medium (DMEM; Thermo Fisher Scientific, Waltham, MA, USA) supplemented with $10 \%$ fetal bovine serum (FBS; Gibco). Cells were grown at $37^{\circ} \mathrm{C}$ in a $5 \% \mathrm{CO}_{2}$ atmosphere saturated with water vapor in a culture medium supplemented with $2 \mathrm{mM}$ l-glutamine, $100 \mathrm{U} / \mathrm{mL}$ gentamycin, and $0.4 \mathrm{mM}$ nonessential amino acids. For all of the cells used, the mycoplasma contamination was checked and excluded by a Mycoplasma stain detection kit (Beyotime, Shanghai, China).

\subsection{Plasmids}

The plasmid NF- $\mathrm{kB}$ used for the NF- $\mathrm{kB}$ reporter assay was a gift from Professor Haixue Zheng (Lanzhou Veterinary Research Institute, Chinese Academy of Auricula Sciences). The plasmids pCAGGs-MGF360-12L, pCAGGs-MGF360-13L, pCAGGs-MGF36014L, pCAGGs-MGF505-1R, pCAGGs-MGF505-2R, and pCAGGs-MGF505-3R were constructed using PCR and pEASY-Basic Seamless Cloning and Assembly Kit (Transgen, Beijing, China, CU201-02). All of these plasmids were confirmed by Sanger sequencing and successfully expressed in PK-15 cells (Figures S2 and S3).

\subsection{Reagents and Antibodies}

The reagents and antibodies used in this study are $\alpha$-Tubulin Rabbit Polyclinal Antibody (Beyotime, Shanghai, China, AF0001); rabbit monoclonal antibodies against phosphoNF-kB p65 (Ser536) (93H1) (Cell Signaling Technology, Danvers, MA, USA, 3033T); rabbit monoclonal antibodies against phospho-IkB $\alpha$ (Ser32) (14D4) (Cell Signaling Technology, Danvers, MA, USA, 2859T); IRDye 800CW Goat (polyclonal) Anti-Rabbit IgG (H + L), Highly Cross Adsorbed (LI-COR, 926-32211); IRDye 800CW Goat (polyclonal) Anti-Mouse IgG (H + L), Highly Cross Adsorbed (LI-COR, 926-32210); Dual-Luciferase Reporter Assay System, Promega, USA, E1910; Annexin V-APC apoptosis detection kit (KeyGEN BioTECH, Nanjing, China, KGA1021). 


\subsection{HAD Assay}

As previously described in [32], primary PAMs were cultured in 96-well plates and infected with 10-fold diluted ASFV. The HAD ${ }_{50}$ was calculated by using the Reed and Muench method [33]. Primary PAMs were infected with GZ201801-ASFV, $\triangle$ MGF360-505RASFV, and $\triangle \mathrm{CD} 2 \mathrm{v} / \triangle \mathrm{MGF} 360-505 \mathrm{R}-\mathrm{ASFV}$ at an MOI of 0.1. HAD assay of the ASFV. The ASFV was inoculated into pig PAMs with $1 \%$ pig blood cells. Cultures were observed for HAD phenomena over 7 days.

\subsection{Polymerase Chain Reaction}

DNA was isolated by Axyprep Body Fluid Viral DNA/RNA Miniprep Kit (Axygen, Union City, CA, USA, SV US, AP-MN-BF-VNA). A total of $1 \mu \mathrm{L}$ of DNA was used for real-time PCR assay using AceQ Universal U+ Probe Master Mix V2 (Vazyme, Nanjing, China, Q513-02). This assay targets the VP72 gene of ASFV [34], and the relative quantity of viral DNA was determined by the CADC p72 primers and probe experiment. Genespecific primer and probe sequences are listed in Supplementary Table S1. Total RNA was isolated by RNAiso Plus (Takara, 9108, Beijing, China). RNA was reverse transcribed into cDNA using the HiScript II 1st Strand cDNA Synthesis Kit ( + gDNA wiper) (Vazyme, China, R212-02). The cDNA was used for real-time PCR assay using ChamQ Universal SYBR qPCR Master Mix (Vazyme, China, Q711-02) kit. The relative quantity of cell RNA was determined by performing a comparative $\mathrm{Ct}(\Delta \Delta \mathrm{Ct})$ experiment using GAPDH as an endogenous control [35-37]. $\Delta \Delta C$ T method assumes $100 \%$ efficiency of qPCR assays. Gene-specific primers sequences were designed using Oligo7 software, listed in Table 1.

Table 1. Primer sequences were used in this study for PCR and real-time PCR in pigs.

\begin{tabular}{cc}
\hline Gene & Primer Sequence $\mathbf{( 5}^{\prime} \mathbf{-} \mathbf{3}^{\prime} \mathbf{)}$ \\
\hline CADC-B646L-rPCRF & ATAGAGATACAGCTCTTCCAG \\
CADC-B646L-rPCRR & GTATGTAAGAGCTGCAGAAC \\
CADC-B646L-Probe & FAM-TATCGATAAGATTGAT-MGB \\
B646L-F & TGAAATAAAATGGAAGCCCACAGATC \\
B646L-R & ACACTGTACAACATTGCGTAAAAGC \\
GAPDH-F & GCAAAGACTGAACCCACTAATT \\
GAPDH-R & TTGCCTCTGTTGTTACTTGGAG \\
IL-1 $\beta-F$ & ACCTGGACCTTGGTTCTCTG \\
IL-1 $\beta-R$ & CATCTGCCTGATGCTCTTG \\
\hline
\end{tabular}

\subsection{Western Blot Analysis}

For the Western blot analysis, cells were lysed in RIPA buffer (Beyotime, Shanghai, China) and denatured by adding $4 \times$ Laemmle SDS-PAGE buffer (containing DLDithiothreitol), followed by heating for $15 \mathrm{~min}$ at $100{ }^{\circ} \mathrm{C}$. The proteins were then separated on SDS-PAGE gels and transferred onto NC membranes by a Trans-Blot Turbo rapid transfer system (Bio-Rad, Hercules, CA, USA) according to the manufacturer's instructions. The membranes were blocked in 5\% defatted milk (dissolved in Tris-buffered saline (TBS)) for $1 \mathrm{~h}$ at $37^{\circ} \mathrm{C}$ and then incubated with a primary antibody for $1 \mathrm{~h}$ at room temperature or overnight at $4{ }^{\circ} \mathrm{C}$. The membranes were then washed extensively in wash buffer (TBS containing $0.1 \%$ Tween 20 ) three times (for 5 min each time) with agitation and incubated with an IRDye $800 \mathrm{CW}$ secondary antibody for $1 \mathrm{~h}$ at $37^{\circ} \mathrm{C}$ according to the species source of the primary antibody. The membranes were washed three times in wash buffer and imaged using an Odyssey (LICOR, Lincoln, NE, USA) to visualize the protein bands. $\alpha$-Tubulin was utilized as a loading control.

\subsection{Transfection and Luciferase Reporter Assays}

Cells were transfected using the Lipofectamine 2000 transfection reagent (Thermo Fisher Scientific, Waltham, MA, USA). Due to cell characteristics, the plasmid transfection efficiency of PK-15 cells is $40-50 \%$. For the NF- $\mathrm{kB}$ reporter assay, NF- $\mathrm{kB}-$ Luc reporter plas- 
mid and luciferase gene internal reference plasmid pRL-TK were mixed and co-transfected with the control empty vector, pCAGGs-MGF360-12L, pCAGGs-MGF360-13L, pCAGGsMGF360-14L, pCAGGs-MGF505-1R, pCAGGs-MGF505-2R, and pCAGGs-MGF505-3R, respectively. At $6 \mathrm{~h}$ post transfection, culture supernatants were replaced with DMEM without FBS. At $24 \mathrm{~h}$ post transfection, cells were collected and subjected to further analysis. Cells were lysed and measured using a dual luciferase assay kit (Promega, Madison, WI, USA) according to the manufacturer's instructions.

\subsection{Flow Cytometry}

After the cells were digested into single cells with $0.25 \%$ trypsin, the cells were washed three times with PBS, and the cells were stained with Annexin V-APC Apoptosis Detection Kit. Use the excitation wavelength of $633 \mathrm{~nm}$ and the maximum emission wavelength of $660 \mathrm{~nm}$ of the Beckman flow cytometer to measure the cell fluorescence. Analysis was carried out on FlowJo software.

\subsection{Statistical Analysis}

All data of each assay represents at least two separate experiments and were determined in triplicate. The results collected from triplicate determinations were analyzed as the means \pm standard deviations (SD). The data was tested by using the KolmogorovSmirnov test (with the Dallal-Wilkinson-Lilliefor $p$ value) method in GraphPad, which showed that these data are normally distributed. Data difference of each experiment was analyzed by One-Way Analysis of Variance (ANOVA) followed by the Tukey's $t$-test in GraphPad Prism 8.0 software (San Diego, CA, USA). ${ }^{*} p<0.05,{ }^{* *} p<0.01$ and ${ }^{* * *} p<0.001$ were considered to be statistically significant at different levels.

\section{Results}

\subsection{Replication of $\triangle C D 2 v / \triangle M G F 360-505 R-A S F V$ in Primary Swine Macrophages}

MGF genes located in the left variable region of the ASFV genome and CD2v gene have been described to be involved in ASFV replication in swine macrophages $[20,21,38,39]$. The in vitro growth characteristics of $\triangle C D 2 v / \triangle M G F 360-505 R-A S F V$ were evaluated in primary swine macrophage cell cultures and the primary cell targeted by ASFV during infection in swine, and compared to those of the parental GZ201801-ASFV strain in a multistep growth curve analysis. GZ201801-ASFV has HAD phenomenon, but $\triangle C D 2 v / \triangle M G F 360$ 505R-ASFV does not (Figure 1A. Cell cultures were infected with these viruses at an MOI of 0.1 , and samples were collected at $0,3,6$, and $12 \mathrm{~h}$ post-infection (hpi) (Figure 1B). $\triangle \mathrm{CD} 2 \mathrm{v} / \triangle \mathrm{MGF360-505R-ASFV}$ displayed a growth kinetic difference from that of the parental GZ201801-ASFV virus. CD2v and MGF360-505R knockout inhibit ASFV replication. The ASFV-p30 protein levels in $\triangle \mathrm{CD} 2 \mathrm{v} / \triangle \mathrm{MGF360-505R-ASFV}$ were significantly lower than in the GZ201801-ASFV group (Figure 1C). And the gray analysis of protein bands was carried out (Figure S4). Therefore, deletion of MGF360 and MGF505 genes in $\triangle C D 2 v / \triangle M G F 360-505 R-A S F V$ does significantly affect the ability of the virus to replicate in primary swine macrophage cultures.

\subsection{Cytopathic Effect of $\triangle C D 2 v / \triangle M G F 360-505 R-A S F V$ in Primary Swine Macrophages}

ASFV has a restricted cellular tropism. The primary target cells for replication are macrophages and monocytes, although replication in dendritic cells has also been reported [10,40,41]. Macrophages and monocytes infected with ASFV will produce cytopathic effects, such as vacuolation and shedding. Compared with the control group, the PAMs cells infected with GZ201801-ASFV produced more severe CPE, while the CPE produced by $\triangle \mathrm{CD} 2 \mathrm{v} / \triangle \mathrm{MGF360-505R-ASFV-infected} \mathrm{PAMs} \mathrm{was} \mathrm{significantly} \mathrm{reduced.} \mathrm{When} \mathrm{GZ201801-}$ ASFV and $\triangle \mathrm{CD} 2 \mathrm{v} / \triangle \mathrm{MGF360-505R-ASFV}$ are co-infected, compared with GZ201801-ASFVinfected PAMs, CPE is significantly reduced (Figure 2), indicating that $\triangle \mathrm{CD} 2 \mathrm{v} / \triangle \mathrm{MGF} 360$ 505R-ASFV can reduce the CPE caused by GZ201801-ASFV-infected PAMs. 
A

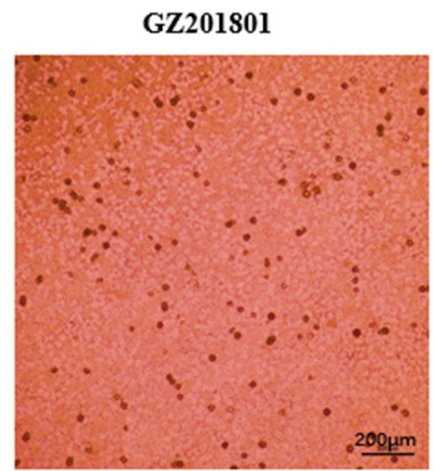

B

B646L gene
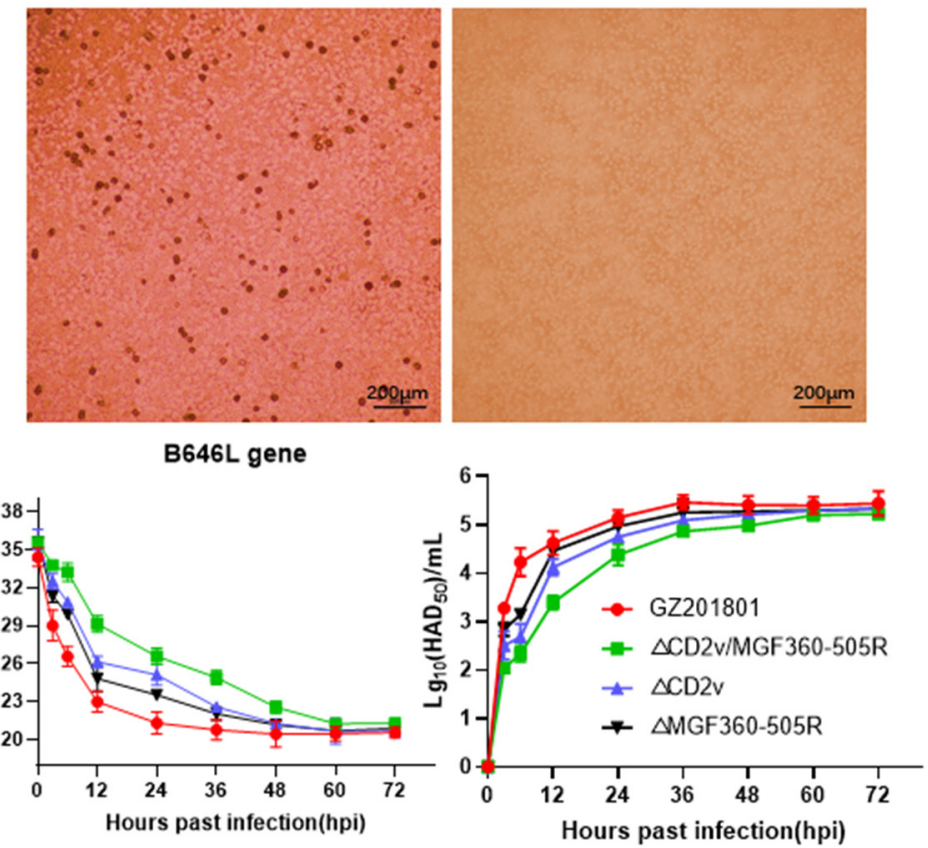

ASFV

C

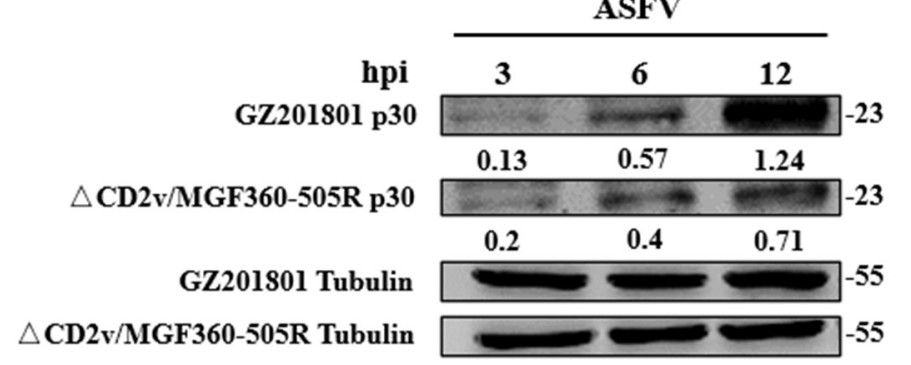

Figure 1. Detection of GZ201801-ASFV, $\triangle$ MGF360-505R-ASFV, $\triangle C D 2 v-A S F V$, and $\Delta C D 2 v / \triangle M G F 360-$ 505R-ASFV in primary PAMs. (A) HAD appeared in primary PAMs infected with GZ201801-ASFV and $\triangle C D 2 v / \triangle M G F 360-505 R-A S F V$. (B) The growth curves of PAMs infected with GZ201801-ASFV and $\triangle \mathrm{CD} 2 \mathrm{v} / \triangle \mathrm{MGF360-505R-ASFV.} \mathrm{(C)} \mathrm{Western} \mathrm{blotting} \mathrm{was} \mathrm{used} \mathrm{to} \mathrm{detect} \mathrm{the} \mathrm{expression} \mathrm{of} \mathrm{p30}$ protein. PAMs were either infected with GZ201801-ASFV, $\triangle$ MGF360-505R-ASFV, $\triangle$ CD2v-ASFV, and $\Delta$ CD2v / $\triangle$ MGF360-505R-ASFV at a MOI of 0.1 .

\subsection{Apoptosis of $\triangle C D 2 v / \triangle M G F 360-505 R-A S F V$ in Primary Swine Macrophages}

Apoptosis represents an important innate cellular mechanism to prevent virus infection, and many viruses have developed strategies in turn, for inhibiting or delaying this cellular response [42]. ASFV-infected cells undergo apoptosis [43] and show the characteristic morphological changes of programmed cell death, including typical membrane blebbing of the infected cell that led to the formation of numerous vesicles containing virus [44] and this could be an efficient system for virus spread. After infection with GZ201801-ASFV, $26.49 \%$ of PAMs were apoptotic, and after infection with CD2v/ $\triangle$ MGF360-505R-ASFV, $8.72 \%$ of PAMs were apoptotic. When GZ201801-ASFV and CD2v/ $\triangle$ MGF360-505R-ASFV were co-infected, $9.35 \%$ of PAMs were apoptotic. After infection with $\triangle$ MGF360-505RASFV, $27.67 \%$ of PAMs were apoptotic, and after infection with $\triangle \mathrm{CD} 2 \mathrm{v}-\mathrm{ASFV}, 30.45 \%$ of PAMs were apoptotic. When GZ201801-ASFV and $\triangle$ MGF360-505R-ASFV were coinfected, 25.99\% of PAMs were apoptotic. When GZ201801-ASFV and $\triangle \mathrm{CD} 2 \mathrm{v}$-ASFV were co-infected, $28.67 \%$ of PAMs were apoptotic (Figure 3). 


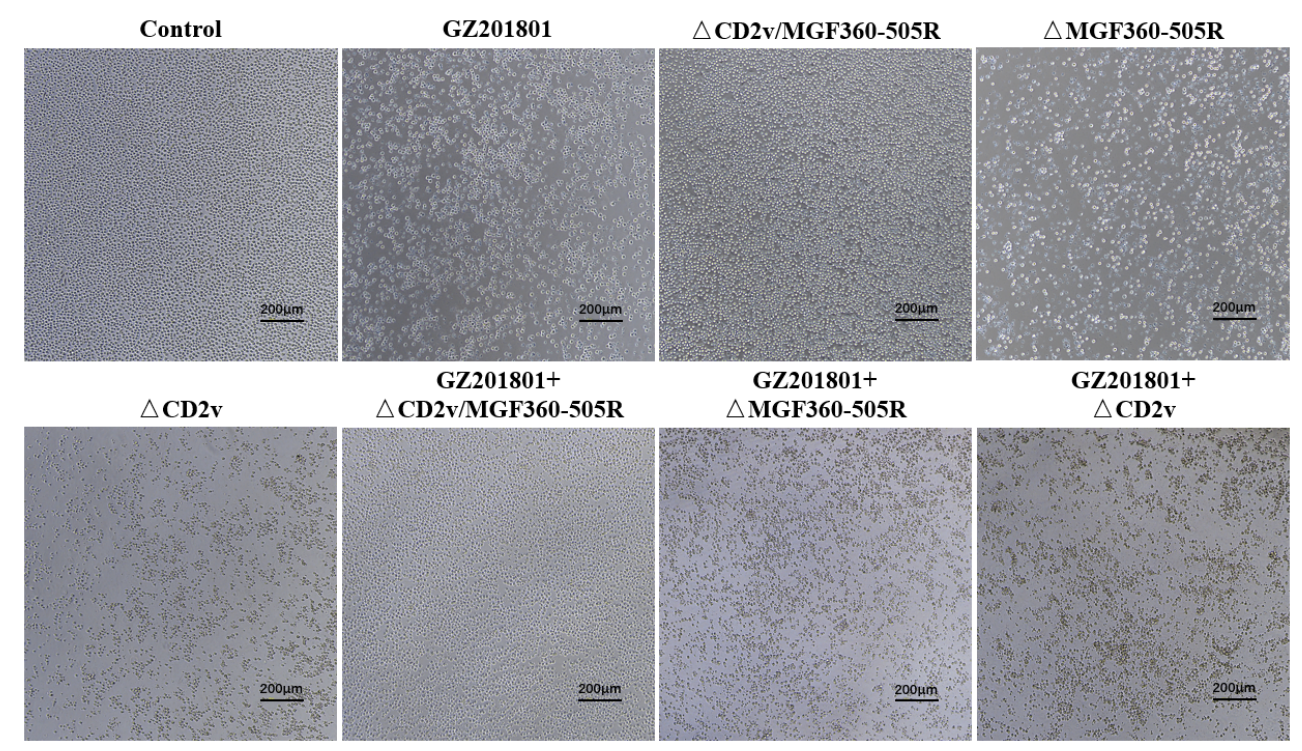

Figure 2. The CPE of infected primary PAMs with GZ201801-ASFV, $\triangle C D 2 v / \triangle M G F 360-505 R-A S F V$, $\triangle$ MGF360-505R-ASFV, and $\triangle$ CD2v-ASFV. GZ201801-ASFV infection of PAMs produces more serious CPE. $\triangle \mathrm{CD} 2 \mathrm{v} / \triangle \mathrm{MGF360-505R-ASFV}$ or co-infection with GZ201801-ASFV and GZ201801-ASFV produced less CPE in PAMs. PAMs were either infected with GZ201801-ASFV, $\triangle C D 2 v / \triangle M G F 360-$ 505R-ASFV, $\triangle$ MGF360-505R-ASFV, or $\triangle \mathrm{CD} 2 \mathrm{v}-\mathrm{ASFV}$ at a MOI of 0.1.

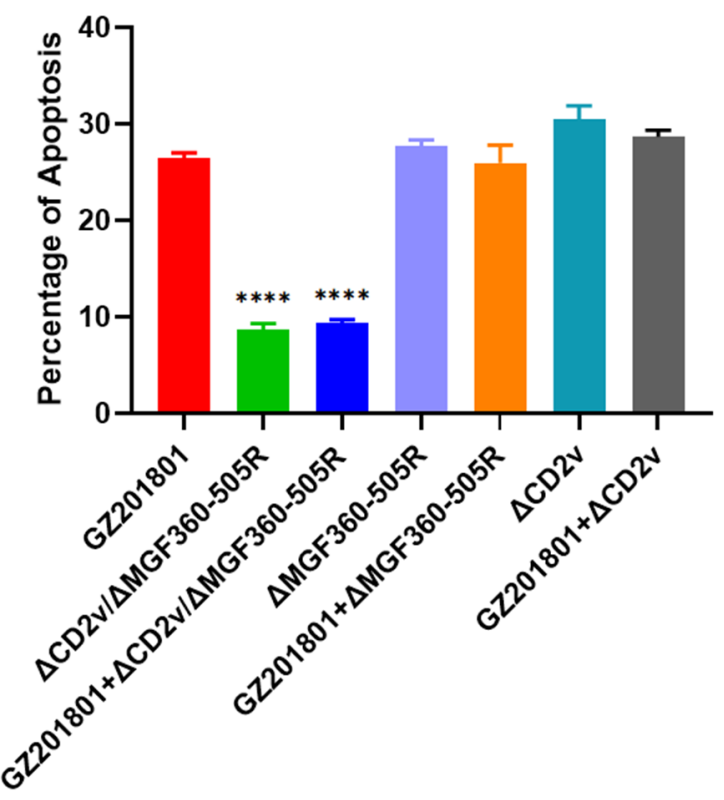

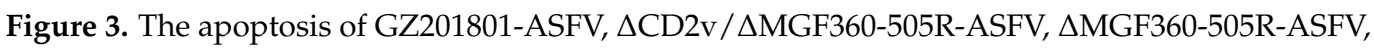
and $\triangle C D 2 v-A S F V$ are infected in primary PAMs. GZ201801-ASFV caused $26.49 \%$ of cell apoptosis after infection with PAMs, $\triangle \mathrm{CD} 2 \mathrm{v} / \triangle \mathrm{MGF} 360-505 \mathrm{R}-\mathrm{ASFV}$ caused $8.72 \%$ of cell apoptosis after infection with PAMs, $\triangle$ MGF360-505R-ASFV caused $27.67 \%$ of cell apoptosis after infection with PAMs, $\Delta C D 2 v$ caused $30.45 \%$ of cell apoptosis after infection with PAMs, GZ201801-ASFV and $\triangle$ CD2v/ $\triangle$ MGF360505R-ASFV caused $9.35 \%$ of cell apoptosis after co-infection with PAMs, GZ201801-ASFV and $\triangle$ MGF360-505R-ASFV caused $27.67 \%$ of cell apoptosis after co-infection with PAMs, and GZ201801ASFV and $\triangle C D 2 v$ caused $30.45 \%$ of cell apoptosis after co-infection with PAMs. PAMs were either infected with GZ201801-ASFV, $\triangle$ CD2v/ MMGF360-505R-ASFV, $\triangle$ MGF360-505R-ASFV, or $\Delta C D 2 v-$ ASFV at a MOI of 0.1. Significant differences compared with the control group are denoted by $* * * *(p<0.001)$. 
3.4. Phospho-NF- $\kappa B$ p65 and $p-I \kappa B$ of $\triangle C D 2 v / \Delta M G F 360-505 R-A S F V$ in Primary Swine Macrophages

Western blotting was used to measure the expression of phospho-NF- $\kappa \mathrm{B}$ p65 protein and $\mathrm{p}$-IкB protein levels at 3,6 , and $12 \mathrm{~h}$ in each group of PAMs. This result suggests that the level of phospho-NF-кB p65 and p-IкB protein increased after GZ201801-ASFV infection, and this effect was abrogated by CD2v and MGF360-505R deficiency. The level of phospho-NF- $\kappa B$ p65 and p-I $\kappa$ B protein after $\triangle$ MGF360-505R-ASFV infection is more than the GZ201801-ASFV infection, and the level of phospho-NF- $\kappa B$ p65 and p-IкB protein after $\triangle \mathrm{CD} 2 \mathrm{v}$-ASFV infection is less than GZ201801-ASFV infection. Expression of Tubulin was used as a positive control (Figure 4). And the gray analysis of protein bands was carried out (Figure S5).

\begin{tabular}{|c|c|c|c|c|}
\hline \multirow[b]{2}{*}{ hpi } & \multicolumn{3}{|c|}{ ASFV } & \\
\hline & 3 & 6 & 12 & \\
\hline \multirow[t]{2}{*}{ GZ201801 PP65 } & $\frac{2+2}{2}$ & +3 & 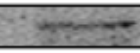 & 55 \\
\hline & 0.24 & 0.25 & 0.32 & \\
\hline \multirow[t]{2}{*}{$\triangle \mathrm{CD2v} / \mathrm{MGF} 360-505 \mathrm{R}$ PP65 } & 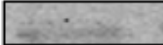 & 2.28 & 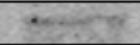 & 65 \\
\hline & 0.17 & 0.25 & 0.29 & \\
\hline \multirow{2}{*}{$\triangle$ MGF360-505R PP65 } & $x+5=$ & $\mathrm{min}$ & $-r$ & -65 \\
\hline & 0.22 & 0.27 & 0.59 & \\
\hline \multirow[t]{2}{*}{$\triangle$ CD2 PP65 } & $=$ & +3 & 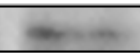 & -65 \\
\hline & 0.13 & 0.15 & 0.2 & \\
\hline \multirow{2}{*}{ GZ201801 РІкB } & 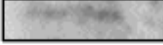 & 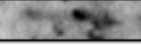 & -4 & -32 \\
\hline & 0.23 & 0.5 & 0.7 & \\
\hline \multirow[t]{2}{*}{$\triangle$ CD2v/MGF360-505R PIкB } & 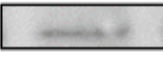 & $m$ & $-\cdots$ & 32 \\
\hline & 0.21 & 0.25 & 0.32 & \\
\hline \multirow[t]{2}{*}{$\triangle$ MGF360-505R PIאB } & $=$ & $-\infty$ & - & -32 \\
\hline & 0.42 & 0.59 & 1.1 & \\
\hline \multirow[t]{2}{*}{$\triangle \mathrm{CD} 2$ РІкВ } & 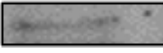 & 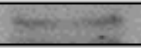 & +4 & -32 \\
\hline & 0.15 & 0.16 & 0.22 & \\
\hline GZ201801 Tubulin & 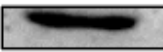 & $=$ & $\longrightarrow$ & -55 \\
\hline D2v/MGF360-505R Tubulin & $=$ & $\longrightarrow$ & $\longrightarrow$ & -55 \\
\hline$\triangle$ MGF360-505R Tubulin & $-\infty$ & $=$ & $=$ & -55 \\
\hline$\triangle$ CD2v Tubulin & 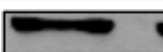 & 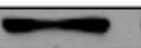 & 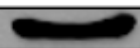 & -55 \\
\hline
\end{tabular}

Figure 4. NF- $\mathrm{KB}$ signaling pathway analysis after ASFV infection. Western blotting was used to measure the expression of PP65 and PIkB protein at 3, 6, and $12 \mathrm{~h}$ in each group of GZ201801ASFV-, $\triangle$ MGF360-505R-ASFV-, $\triangle$ CD2v-ASFV-, and $\triangle$ CD2v/ $\triangle$ MGF360-505R-ASFV-infected PAMs. Expression of tubulin was used as a positive control. PAMs were either infected with GZ201801-ASFV or $\triangle \mathrm{CD} 2 \mathrm{v} / \triangle \mathrm{MGF360-505R-ASFV}$ at a MOI of 0.1.

\subsection{MGF360-12L, MGF360-13L, and MGF505-2R Inhibit NF-kB Promoter}

The luciferase reporter gene internal reference plasmids pRL-TK and NF- $K B-L u c$ reporter plasmids were mixed, and co-transfected with pCAGGs-MGF360-12L, pCAGGsMGF360-13L, pCAGGs-MGF360-14L, pCAGGs-MGF505-1R, pCAGGs-MGF505-2R, and pCAGGs-MGF505-3R plasmids separately, and Luciferase Reporter Assays were performed. This result suggests that MGF360-12L, MGF360-13L, and MGF505-2R of ASFV MGF360505R significantly inhibit the NF- $\mathrm{kB}$ promoter compared with the control empty vector (Figure 5). 


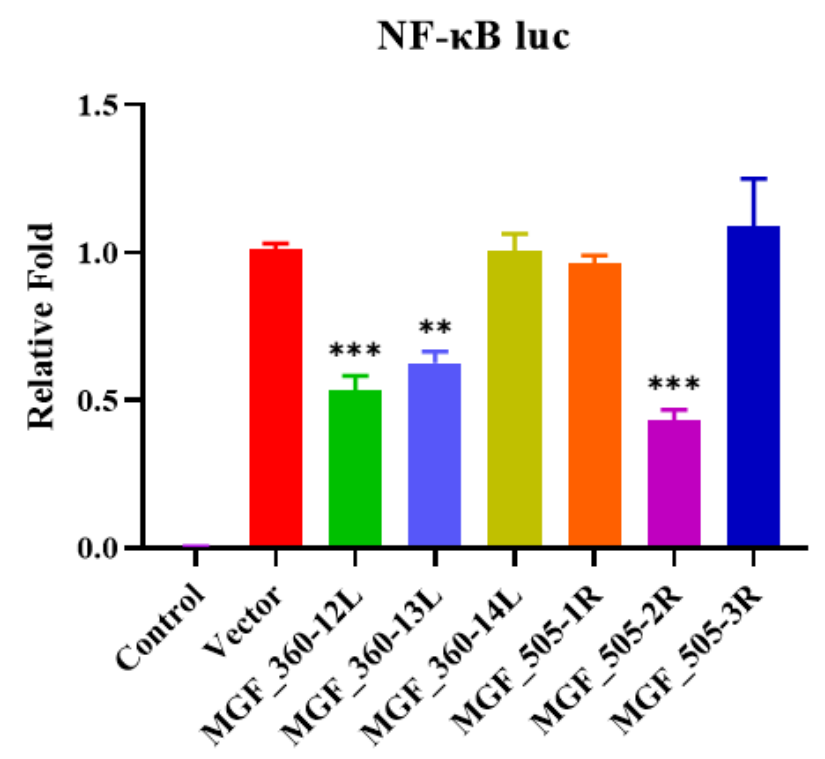

Figure 5. MGF360-12L, MGF360-13L, and MGF505-2R interfere with the NF- $\kappa$ B signaling pathway. Plasmid encoding MGF360-12L, MGF360-13L, MGF360-14L, MGF505-1R, MGF505-2R, MGF505-3R, or empty vectors were co-transfected into PK-15 cells with the NF-kB-Luc promoter reporter plasmid and with pRL-TK. After $24 \mathrm{~h}$, luciferase activity was determined by dual-luciferase assay. Each datum represents results of three independent experiments (means \pm SD). Significant differences compared with the control group are denoted by ** $(p<0.01)$ and ${ }^{* * *}(p<0.001)$.

\section{6. $\triangle C D 2 v / \triangle M G F 360-505 R-A S F V$ Inhibits the Expression of IL-1 $\beta$ mRNA}

To study the changes of IL-1 $\beta$ after the PAMs were infected with GZ201801-ASFV or $\Delta \mathrm{CD} 2 \mathrm{v} / \triangle \mathrm{MGF} 360-505 \mathrm{R}-\mathrm{ASFV}$, IL-1 $\beta$ mRNA expression was measured by real-time RT-PCR. The expression of IL-1 $\beta$ mRNA in the GZ201801-ASFV infection group at $3 \mathrm{~h}$ and $12 \mathrm{~h}$ increased with the time of infection. The expression of IL-1 $\beta$ mRNA in the $\triangle C D 2 v / \triangle M G F 360-505 R-A S F V$ infection group was significantly lower than in the GZ201801ASFV infection group, at $3 \mathrm{~h}$ and $12 \mathrm{~h}$ (Figure 6).

\section{IL-1及}

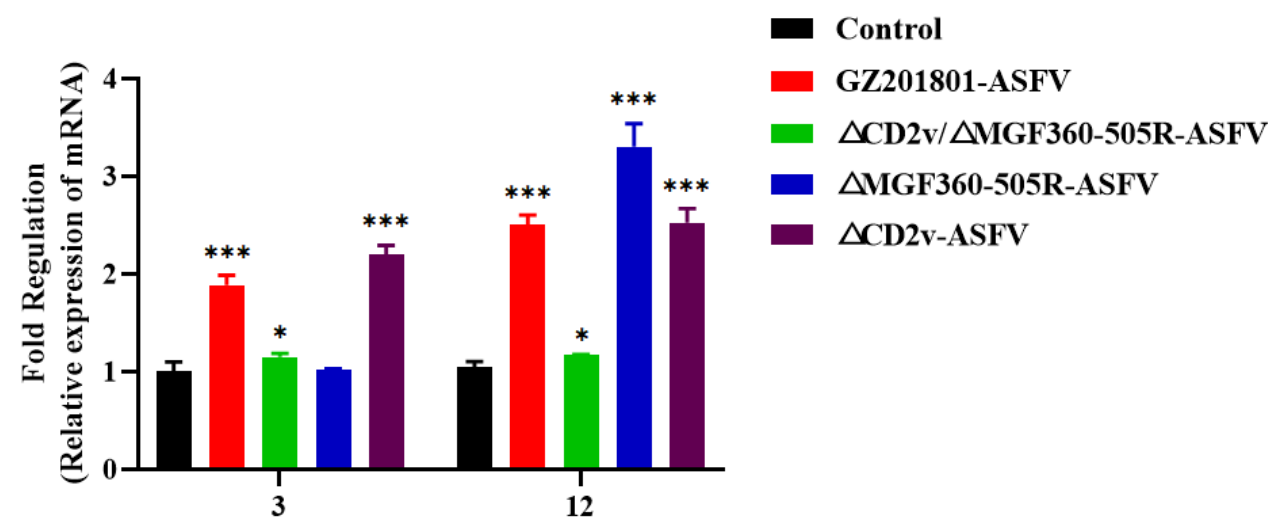

Hours past infection(hpi)

Figure 6. Changes in expression of IL-1 $\beta$ mRNA. Real-time RT-PCR was used to assess the mRNA expression of IL-1 $\beta$ in PAMs incubated with GZ201801-ASFV, $\triangle$ CD2v / $\triangle$ MGF360-505R-ASFV $\Delta C D 2 v$, and $\triangle$ MGF360-505R-ASFV after $0,3,6$, and $12 \mathrm{~h}$. Increased expression of IL- $1 \beta$ mRNA was seen in GZ201801-ASFV-infected cells and this effect was abrogated by CD2v and MGF360-505R deficiency. Each datum represents results of three independent experiments (means \pm SD). Significant differences compared with the control group are denoted by $*(p<0.05)$ and ${ }^{* * *}(p<0.001)$. PAMs were either infected with GZ201801-ASFV or $\triangle \mathrm{CD} 2 \mathrm{v} / \triangle \mathrm{MGF360-505R-ASFV}$ at a MOI of 0.1. 


\section{Discussion}

ASFV infection of domestic pigs or wild boars can cause severe hemorrhagic diseases, and the mortality rate is as high as $100 \%$ [45]. Because ASFV and the host have a complex interaction mechanism, ASFV can evade the host immune system [4]. Some pathogens kill macrophages by inducing apoptosis, thereby reducing the phagocytic ability of phagocytes to pathogens [46]. Using a DNA homologous recombination technique [1], we constructed $\triangle \mathrm{CD} 2 \mathrm{v} / \triangle \mathrm{MGF} 360-505 \mathrm{R}-\mathrm{ASFV}$ viruses by deleting gene segments encoding seven different proteins, includingMGF505-1R, MGF505-2R, MGF505-3R, MGF360-12L, MGF360-13L, MGF360-14L, and CD2v, which have previously been observed to be important for the virulence of different ASFVs [1,47]. This study shows that GZ201801-ASFV has obvious CPE after being infected with PAMs, while $\triangle \mathrm{CD} 2 \mathrm{v} / \triangle \mathrm{MGF360-505R-ASFV} \mathrm{infection} \mathrm{pro-}$ duces significantly lower CPE compared with GZ201801-ASFV. Through flow cytometry, it was found that the percentage of PAMs apoptosis caused by $\triangle C D 2 v / \triangle M G F 360-505 R-$ ASFV infection was significantly lower than that of GZ201801-ASFV infection. When GZ201801-ASFV and $\triangle \mathrm{CD2v} / \triangle \mathrm{MGF360-505R-ASFV}$ are co-infected, the CPE of PAMs and the percentage of PAMs cell apoptosis are also significantly lower than that of the GZ201801-ASFV infection.

Apoptotic macrophages can also cause the host's inflammatory response by secreting pro-inflammatory cytokines [23]. In recent years, more and more studies have been conducted on ASFV infection in order to activate the host NF- $\mathrm{kB}$ signaling pathway. Although different viruses activate the upstream signaling molecules of the NF- $\mathrm{KB}$ pathway by different mechanisms, they will eventually converge the signal to the IкB kinase (IKK) complex. It activates IKB to cause a cascade of signals, and finally initiates the transcription of target genes [48]. Therefore, it shows that IKK, the IкB kinase complex, is a key node that activates the NF- $\mathrm{kB}$ signaling pathway caused by various external stimuli. The cytokines and chemokines (TNF- $\alpha$ and IL-1 $\beta$ ) produced after the activation of the NF- $\mathrm{kB}$ signaling pathway can reactivate the NF- $\mathrm{kB}$ signaling pathway and cause a cascade reaction in the host [48]. Different signaling pathways respond to different levels of IL-1 $\beta$, which can lead to host genotoxic damage and cell apoptosis, or affect cell growth. In the environment of high levels of IL-1 $\beta$, cells that have undergone genotoxic damage in the host will participate in the apoptosis pathway [49]. This study shows that GZ201801-ASFV infection of PAMs activates the NF- $\mathrm{KB}$ signaling pathway and promotes the expression of IL- $1 \beta$. However, the up-regulated expression levels of phospho-NF- $\kappa B$ p65 and p-IкB proteins and IL- $1 \beta$ by $\triangle \mathrm{CD} 2 \mathrm{v} / \triangle \mathrm{MGF} 360-505 \mathrm{R}-\mathrm{ASFV}$ infection was significantly lower than that of GZ201801-ASFV. When the MGF360-505 deletion strain is infected with PAMs, it activates the host's NF- $k B$ signaling pathway, while the CD2v-deficient strain inhibits the host's NF- $\kappa B$ signaling pathway after infecting PAMs, indicating that MGF360-505 has the effect of inhibiting NF- $\mathrm{KB}$ and $\mathrm{CD} 2 \mathrm{v}$ has the effect of activating NF- $\mathrm{kB}$. We further found that MGF360-12L, MGF360-13L, and MGF-505-2R suppress the promoter activity of NF- $\mathrm{kB}$, and $\mathrm{CD} 2 \mathrm{v}$ activates the NF- $\mathrm{KB}$ signaling pathway.

The activation and regulation mechanism of apoptosis is an extremely complex process regulated by the body's internal mechanisms, and it participates in a variety of life activities. In depth research on the molecular mechanism of ASFV infection and activation of cell apoptosis will help to develop and use cell apoptosis as a new weapon against ASFV replication and provide a theoretical basis for the prevention and treatment of ASF. In summary, our data demonstrated that $\triangle \mathrm{CD} 2 \mathrm{v} / \triangle \mathrm{MGF} 360-505 \mathrm{R}-\mathrm{ASFV}$ infection caused PAMs apoptosis and the expression levels of ASFV p30 protein are significantly lower than the GZ201801-ASFV infection. Also, $\triangle \mathrm{CD} 2 \mathrm{v} / \triangle \mathrm{MGF360-505R-ASFV}$ infection upregulates the expression levels of phospho-NF- $\mathrm{BB}$ p 65 and $\mathrm{p}-\mathrm{I} \kappa \mathrm{B}$ proteins and IL- $1 \beta$ production are significantly lower than the GZ201801-ASFV infection. Additionally, MGF360-12L, MGF360-13L, and MGF-505-2R suppress the promoter activity of NF- $\mathrm{kB}$ (Figure 7). These findings suggest that $\triangle \mathrm{CD} 2 \mathrm{v} / \triangle \mathrm{MGF} 360-505 \mathrm{R}-\mathrm{ASFV}$ reduces the apoptosis of PAMs by inhibiting the NF- $\mathrm{KB}$ signaling pathway and IL- $1 \beta$, which might provide a theoretical basis for the development of an effective vaccine for ASFV. 


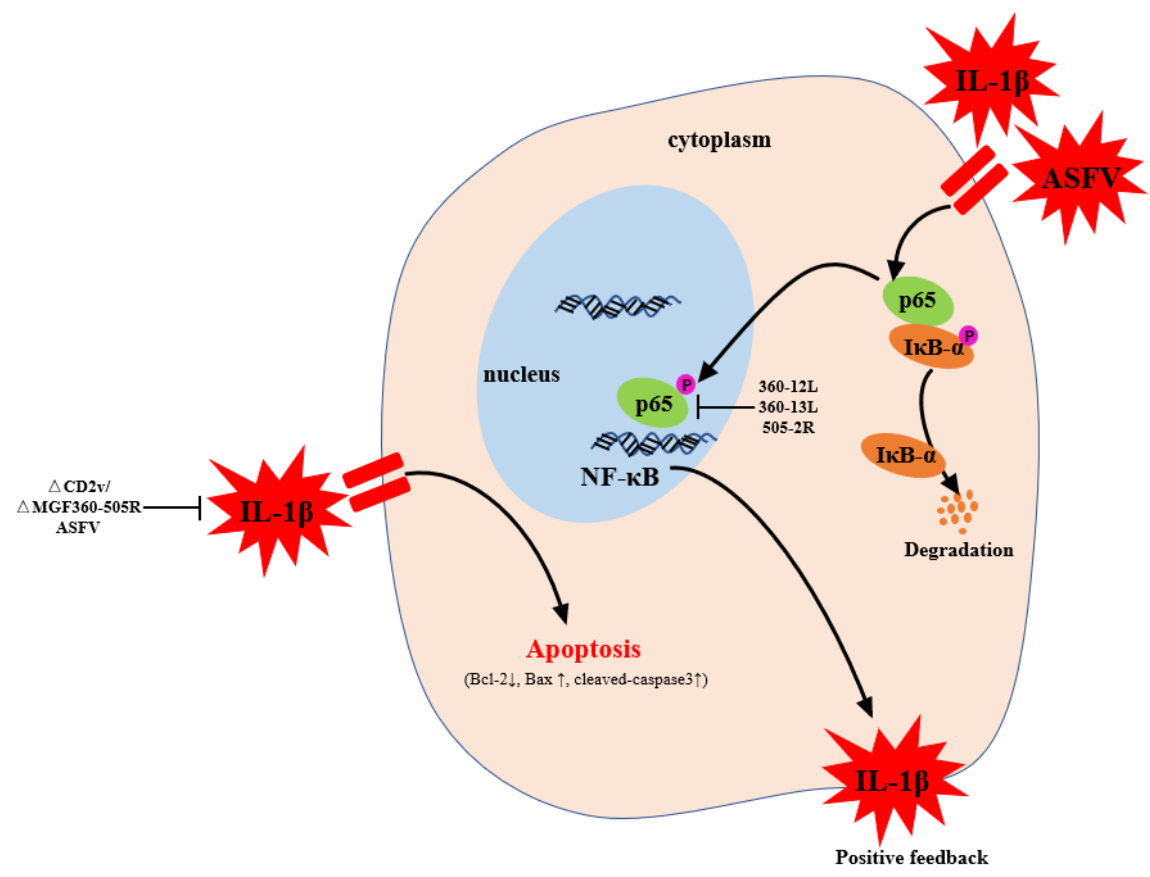

Figure 7. The mechanism of $\triangle \mathrm{CD} 2 \mathrm{v} / \triangle \mathrm{MGF} 360-505 \mathrm{R}-\mathrm{ASFV}$ inhibits apoptosis after infecting PAMs cells. After infection with PAMs, GZ201801-ASFV promotes the release of IL-1 $\beta$ to induce cell apoptosis. After $\triangle C D 2 v / \triangle M G F 360-505 R-A S F V$ infection with PAMs, the activation of NF- $\kappa B$ pathway and IL-1 $\beta$ are significantly lower than GZ201801-ASFV. Therefore, the percentage of apoptosis induced by $\triangle C D 2 v / \triangle$ MGF360-505R-ASFV infecting PAMs was significantly lower than in GZ201801-ASFV.

Supplementary Materials: The following are available online at https: / www.mdpi.com/article / 10.3390 /vaccines9111371/s1, Figure S1: Western blotting was used to detect the expression of p30 protein, Figure S2: Detection of PAMs cell purity, Figure S3: NF-kB signaling pathway analysis after ASFV infection, Figure S4: Construct MGF360-505R plasmids, Figure S5: All of these plasmids were successfully expressed in PK-15 cells.

Author Contributions: Conceptualization, L.G. and G.Z.; methodology, Q.G.; software, Y.Y.; validation, W.Q., J.Z. and Y.L.; formal analysis, H.W.; investigation, X.C. (Xiongnan Chen); resources, G.Z.; data curation, Y.Y.; writing—original draft preparation, Q.G.; writing—review and editing, Q.G.; visualization, W.Q.; supervision, Z.H.; project administration, X.C. (Xiaojun Chen); funding acquisition, R.X. All authors have read and agreed to the published version of the manuscript.

Funding: This research was funded by the National Natural Science Foundation of China [grant number 31941004], the Key-Area Research and Development Program of Guangdong Province [grant number 2019B020211003], Science and Technology Project of Guangdong Pig Industrial Park [grant number GDSCYY2020-024], and China Agriculture Research System of MOF and MARA [grant number cars35].

Institutional Review Board Statement: Not applicable.

Informed Consent Statement: Not applicable.

Conflicts of Interest: The authors declare no competing interest.

\section{References}

1. O’Donnell, V.; Holinka, L.G.; Gladue, D.; Sanford, B.; Krug, P.W.; Lu, X.; Arzt, J.; Reese, B.; Carrillo, C.; Risatti, G.R.; et al. African Swine Fever Virus Georgia Isolate Harboring Deletions of MGF360 and MGF505 Genes Is Attenuated in Swine and Confers Protection against Challenge with Virulent Parental Virus. J. Virol. 2015, 89, 6048-6056. [CrossRef] [PubMed]

2. Dixon, L.K.; Sun, H.; Roberts, H. African swine fever. Antivir. Res. 2019, 165, 34-41. [CrossRef] [PubMed]

3. Pikalo, J.; Zani, L.; Hühr, J.; Beer, M.; Blome, S. Pathogenesis of African swine fever in domestic pigs and European wild boar-Lessons learned from recent animal trials. Virus Res. 2019, 271, 197614. [CrossRef] [PubMed] 
4. Golding, J.P.; Goatley, L.; Goodbourn, S.; Dixon, L.K.; Taylor, G.; Netherton, C.L. Sensitivity of African swine fever virus to type I interferon is linked to genes within multigene families 360 and 505. Virology 2016, 493, 154-161. [CrossRef] [PubMed]

5. Thomson, G.R.; Onderstepoort, J. The epidemiology of African swine fever: The role of free-living hosts in Africa. Vet. Res. 1985, 52, 201-209.

6. Cisek, A.A.; Dąbrowska, I.; Gregorczyk, K.P.; Wyżewski, Z. African Swine Fever Virus: A new old enemy of Europe. Ann. Parasitol. 2016, 62, 161-167.

7. Zhuo, Y.; Guo, Z.; Ba, T.; Zhang, C.; He, L.; Zeng, C.; Dai, H. African Swine Fever Virus MGF360-12L Inhibits Type I Interferon Production by Blocking the Interaction of Importin $\alpha$ and NF-kB Signaling Pathway. Virol. Sinic. 2021, 36, 176-186. [CrossRef]

8. Zhao, D.; Liu, R.; Zhang, X.; Li, F.; Wang, J.; Zhang, J.; Liu, X.; Wang, L.; Zhang, J.; Wu, X.; et al. Replication and virulence in pigs of the first African swine fever virus isolated in China. Emerg. Microbes Infect. 2019, 8, 438-447. [CrossRef]

9. Afonso, C.L.; Piccone, M.E.; Zaffuto, K.M.; Neilan, J.; Kutish, G.F.; Lu, Z.; Balinsky, C.A.; Gibb, T.R.; Bean, T.J.; Zsak, L.; et al. African swine fever virus multigene family 360 and 530 genes affect host interferon response. J. Virol. 2004, 78, 1858-1864. [CrossRef]

10. Correia, S.; Ventura, S.; Parkhouse, R.M. Identification and utility of innate immune system evasion mechanisms of ASFV. Virus Res. 2013, 173, 87-100. [CrossRef]

11. Rodriguez, J.M.; Yanez, R.J.; Almazan, F.; Vinuela, E.; Rodriguez, J.F. African swine fever virus encodes a Cd2 homolog responsible for the adhesion of erythrocytes to infected-cells. J. Virol. 1993, 67, 5312-5320. [CrossRef]

12. Goatley, L.C.; Dixon, L.K. Processing and localization of the african swine fever virus CD2v transmembrane protein. J. Virol. 2011, 85, 3294-3305. [CrossRef] [PubMed]

13. Kay-Jackson, P.C.; Goatley, L.C.; Cox, L.; Miskin, J.E.; Parkhouse, R.M.E.; Wienands, J.; Dixon, L.K. The CD2v protein of African swine fever virus interacts with the actin-binding adaptor protein SH3P7. J. Gen. Virol. 2004, 85, 119-130. [CrossRef] [PubMed]

14. Borca, M.V.; Carrillo, C.; Zsak, L.; Laegreid, W.W.; Kutish, G.F.; Neilan, J.G.; Burrage, T.G.; Rock, D.L. Deletion of a CD2-like gene, 8-DR, from African swine fever virus affects viral infection in domestic swine. J. Virol. 1998, 72, 2881-2889. [CrossRef] [PubMed]

15. Alejo, A.; Matamoros, T.; Guerra, M.; Andres, G. A proteomic atlas of the african swine fever virus particle. J. Virol. 2018, 92, e01293-18. [CrossRef]

16. Monteagudo, P.L.; Lacasta, A.; Lopez, E.; Bosch, L.; Collado, J.; Pina-Pedrero, S.; Correa-Fiz, F.; Accensi, F.; Navas, M.J.; Vidal, E.; et al. BA71 Delta cd2: A new recombinant live attenuated african swine fever virus with cross-protective capabilities. J. Virol. 2017, 91, e01058-17. [CrossRef]

17. Almendral, J.M.; Almazán, F.; Blasco, R.; Viñuela, E. Multigene families in African swine fever virus: Family 110. J. Virol. 1990, 64, 2064-2072. [CrossRef]

18. González, A.; Calvo, V.; Almazán, F.; Almendral, J.M.; Ramírez, J.C.; de la Vega, I.; Blasco, R.; Viñuela, E. Multigene families in African swine fever virus: Family 360. J. Virol. 1990, 64, 2073-2081. [CrossRef]

19. Yozawa, T.; Kutish, G.; Afonso, C.; Lu, Z.; Rock, D. Two Novel Multigene Families, 530 and 300, in the Terminal Variable Regions of African Swine Fever Virus Genome. Virology 1994, 202, 997-1002. [CrossRef]

20. Zsak, L.; Lu, Z.; Burrage, T.G.; Neilan, J.G.; Kutish, G.F.; Moore, D.M.; Rock, D.L. African Swine Fever Virus Multigene Family 360 and 530 Genes Are Novel Macrophage Host Range Determinants. J. Virol. 2001, 75, 3066-3076. [CrossRef]

21. Zsak, L.; Neilan, J.G. Regulation of Apoptosis in African Swine Fever Virus-Infected Macrophages. Sci. World J. 2002, 2, 1186-1195 [CrossRef] [PubMed]

22. Burrage, T.G.; Lu, Z.; Neilan, J.G.; Rock, D.L.; Zsak, L. African Swine Fever Virus Multigene Family 360 Genes Affect Virus Replication and Generalization of Infection in Ornithodoros porcinus Ticks. J. Virol. 2004, 78, 2445-2453. [CrossRef] [PubMed]

23. Lawrence, T. The nuclear factor NF-kappaB pathway in inflammation. Cold Spring Harb. Perspect. Biol. 2009, 1, 1651. [CrossRef] [PubMed]

24. Beg, A.A.; Baltimore, D. An essential role for NF-kappaB in preventing TNF-alpha-induced cell death. Science 1996, 274, 782-784. [CrossRef]

25. Dejardin, E.; Droin, N.M.; Delhase, M.; Haas, E.; Cao, Y.; Makris, C.; Li, Z.W.; Karin, M.; Ware, C.F.; Green, D.R.; et al. The lymphotoxin-beta receptor induces different patterns of gene expression via two NF-kappaB pathways. Immunity 2002, 17, 525-535. [CrossRef]

26. Bergmann, S.; Elbahesh, H. Targeting the proviral host kinase, FAK, limits influenza a virus pathogenesis and NFkB-regulated pro-inflammatory responses. Virology 2019, 534, 54-63. [CrossRef] [PubMed]

27. Piotrowska, A.; Izykowska, I.; Podhorska-OkoŁów, M.; Zabel, M.; Dziegiel, P. The structure of NF-kappaB family proteins and their role in apoptosis. Postępy Hig. I Med. Doświadczalnej 2008, 62, 64-74.

28. Zou, L.; Lei, H.; Shen, J.; Liu, X.; Zhang, X.; Wu, L.; Hao, J.; Jiang, W.; Hu, Z. HO-1 induced autophagy protects against IL-1 $\beta$-mediated apoptosis in human nucleus pulposus cells by inhibiting NF-kB. Aging 2020, 12, 2440-2450. [CrossRef]

29. Saade, G.; Deblanc, C.; Bougon, J.; Marois-Créhan, C.; Fablet, C.; Auray, G.; Belloc, C.; Leblanc-Maridor, M.; Gagnon, C.A.; Zhu, J.; et al. Coinfections and their molecular consequences in the porcine respiratory tract. Vet. Res. 2020, 51, 80.

30. Lau, S.K.; Chu, P.G.; Weiss, L.M. CD163: A Specific Marker of Macrophages in Paraffin-Embedded Tissue Samples. Am. J. Clin. Pathol. 2004, 122, 794-801. [CrossRef]

31. Munday, J.; Floyd, H.; Crocker, P.R. Sialic acid binding receptors (siglecs) expressed by macrophages. J. Leukoc. Biol. 1999, 66, 705-711. [CrossRef] 
32. Breese, S.S.J.; DeBoer, C.J. Electron microscope observations of African swine fever virus in tissue culture cells. Virology 1966, 28, 420-428. [CrossRef]

33. Rowlands, R.J.; Michaud, V.; Heath, L.; Hutchings, G.; Oura, C.; Vosloo, W.; Dwarka, R.; Onashvili, T.; Albina, E.; Dixon, L.K. African Swine Fever Virus Isolate, Georgia, 2007. Emerg. Infect. Dis. 2008, 14, 1870-1874. [CrossRef] [PubMed]

34. Donald, P.K.; Scott, M.R.; Geoffrey, H.H.; Sylvia, S.G.; Sylvia, J.W.; Linda, K.D.; Armanda, D.B.; Trevor, W.D. Development of a TaqMan ${ }^{\circledR}$ PCR assay with internal amplification control for the detection of African swine fever virus. J. Virol. Methods 2003, 107, 53-61.

35. Livak, K.J.; Schmittgen, T.D. Analysis of relative gene expression data using real-time quantitative PCR and the 2(-Delta Delta C(T)) Method. Methods 2001, 25, 402-408. [CrossRef]

36. Sabal, C.; Gustavo, A.D.; Sushil, K.; Daniel, L.R. African Swine Fever Virus CD2v Protein Induces $\beta$-Interferon Expression and Apoptosis in Swine Peripheral Blood Mononuclear Cells. Viruses 2021, 13, 1480.

37. Zhuo, Y.; Guo, Z.; Ba, T.; Zhang, C.; He, L.; Zeng, C.; Dai, H. African swine fever virus MGF505-11R inhibits type I interferon production by negatively regulating the cGAS-STING-mediated signaling pathway. Vet. Microbiol. 2021, $263,109265$.

38. Krug, P.W.; Holinka, L.G.; O’Donnell, V.; Reese, B.; Sanford, B.; Fernandez-Sainz, I.; Gladue, D.; Arzt, J.; Rodriguez, L.; Risatti, G.R.; et al. The Progressive Adaptation of a Georgian Isolate of African Swine Fever Virus to Vero Cells Leads to a Gradual Attenuation of Virulence in Swine Corresponding to Major Modifications of the Viral Genome. J. Virol. 2014, 89, 2324-2332. [CrossRef] [PubMed]

39. Dixon, L.K.; Islam, M.; Nash, R.; Reis, A.L. African swine fever virus evasion of host defences. Virus Res. 2019, 266, 25-33. [CrossRef]

40. Haig, D.M. Subversion and piracy: DNA viruses and immune evasion. Res. Vet. Sci. 2001, 70, 205-219. [CrossRef]

41. Janeway, C.A.; Medzhitov, R. Innate immune recognition. Ann. Rev. Immunol. 2002, 20, 197-216. [CrossRef] [PubMed]

42. Benedict, C.A.; Norris, P.S.; Ware, C.F. To kill or be killed: Viral evasion of apoptosis. Nat. Immunol. 2002, 3, 1013-1018. [CrossRef] [PubMed]

43. Ramiro-Ibáñez, F.; Ortega, A.; Escribano, J.M.; Alonso, C. Apoptosis: A Mechanism of Cell Killing and Lymphoid Organ Impairment during Acute African Swine Fever Virus Infection. J. Gen. Virol. 1996, 77, 2209-2219. [CrossRef] [PubMed]

44. Hernaez, B.; Escribano, J.M.; Alonso, C. Visualization of the African swine fever virus infection in living cells by incorporation into the virus particle of green fluorescent protein-p54 membrane protein chimera. Virology 2006, 350, 1-14. [CrossRef]

45. Galindo, I.; Alonso, C. African Swine Fever Virus: A Review. Viruses 2017, 9, 103. [CrossRef]

46. Hilbi, H.; Zychlinsky, A.; Sansonetti, P.J. Macrophage apoptosis in microbial infections. Parasitology 1997, 115, 79-87. [CrossRef]

47. Reis, A.L.; Abrams, C.C.; Goatley, L.C.; Netherton, C.; Chapman, D.G.; Cordón, P.S.; Dixon, L.K. Deletion of African swine fever virus interferon inhibitors from the genome of a virulent isolate reduces virulence in domestic pigs and induces a protective response. Vaccine 2016, 34, 4698-4705. [CrossRef]

48. Zhang, B.; Lu, Y.; Campbell-Thompson, M.; Spencer, T.; Song, S. Alpha1-antitrypsin protects beta-cells from apoptosis. Diabetes 2007, 56, 1316-1323. [CrossRef]

49. Roy, D.; Sarkar, S.; Felty, Q. Levels of IL-1 beta control stimulatory/inhibitory growth of cancer cells. Front. Biosci. 2006, 11, 889-898. [CrossRef] 